\title{
Arduino-based Sensor Device - An Engineering Physics Second- year Design Project within the Engineering Design and Practice Sequence (EDPS) of the Queen's Engineering Professional Spine
}

\author{
Robert Knobel, Mark Chen, and Lynann Clapham \\ Department of Physics, Engineering Physics, and Astronomy, Queen's University \\ 1c2@queensu.ca
}

\begin{abstract}
In 2011, Queen's Engineering began rollout of its "Engineering Design and Practice Sequence (EDPS)". The EDPS is a "professional spine" sequence of courses over four years, meant to address and incorporate into all of its engineering programs the majority of the 12 Graduate attributes required by the Canadian Engineering Accreditation Board (CEAB). In year 1, the first EDPS course - Engineering Practice I introduces students to engineering design and problem solving, but with little formal instruction in the design process and engineering tools. Formal instruction in these aspects comes in second year, in Engineering Design and Practice II (course number APSC200). Finally, in third and fourth year, students undertake significant design projects in their discipline.

The second-year version of the professional spine, APSC200, is a one-term course taken by all students. This begins with a 6-week Faculty-wide course module, followed by a 6-week program-specific module. In the first Faculty-wide segment, students learn the design process problem definition and scope, idea generation and broadening tools, decision-making tools, economic analysis, stakeholders, risk, and safety. Students are exposed to the necessity of formal design techniques via a zero-level "P0" project, and taught these techniques during a more extensive $P 1$ project.
\end{abstract}

The second 6 weeks of APSC200 involves a discipline-specific project $(P 2)$ in which the student teams practice the skills introduced in the earlier portion of the course while working through a design project chosen to emphasize the skills of their program. This paper focusses on the development and implementation of the P2 project for students in the Queen's Engineering Physics program. The goal of this project is to introduce discipline-specific tools and techniques, to excite students in their chosen engineering discipline, and to put into practice the formal design techniques introduced earlier.

The P 2 project developed for Engineering Physics was entitled a "Compact Environmental Monitoring Station”. The premise was that the Ontario Ministry of the Environment (MOE) issued an RFP for small, cheap sensor devices that could be provided to every Ontario household, and set up to "crowdsource" environmental data for the MOE. Student teams were required to research and justify which environmental parameters would be appropriate for their monitoring device, decide on parameters to monitor, design the device, and build a working prototype of the device.

The device specifications required the use of an Arduinobased platform, interfacing the chosen sensor(s) to a laptop computer using MatLab. Since only some students were familiar with Arduinos and MatLab, two "just in time" workshops were delivered on these topics, using a "flipped lab" approach.

For the prototype design and build, students had only 4 weeks and a budget of \$100. Arduino boards and some basic sensors were supplied, with students able to source and purchase other components within their budget. The prototype-build provided the students with a valuable hands-on experience and also helped them to fully appreciate unexpected practical design constraints. Given the short timeframe (4-weeks) for the design and build, prototypes were very impressive, with many including solar power or rechargeable batteries, Bluetooth connectivity, 3-D printed packaging, IPhone or Android apps, as well as calibration functions.

This paper will summarize the development of this Engineering Physics $P 2$ module, and will report on the first year of offering it in its current format.

Keywords: design, projects, Arduino, sensor

\section{INTRODUCTION}

In 2011, the Faculty of Engineering and Applied Science at Queen's University began the rollout of its new Engineering Design and Practice Sequence (EDPS). This project-based, four-year sequence is core for all engineering students, and develops competence in many of the graduate attributes expected by the engineering profession. The overall curriculum plan for the EDPS (stages I-IV) involves the repetition of common concepts and objectives across 4 years, with more scaffolding in early years and an increasing project complexity over time. First year students receive a two-term, three-module, project-based course focusing on complex problem solving, experimental design, and engineering design. The third module is a team-based client project where students 
are introduced to information literacy, the design process, teaming, communications, ethics, economics, project management and professionalism. More formal instruction in these aspects comes in an initial "common" 6 weeks of the second year Engineering Design and Practice II course (APSC2000), and then is practiced in a discipline-specific project (P2) in the second 6 weeks of APSC200. The discipline-specific P2 portion of APSC200 is the subject of this paper. Finally, in third and fourth year of the EDPS, students undertake significant design projects in their discipline. Papers detailing the full EDPS course sequence can be found in references [2] and [4].

\subsection{Structure and Content of Engineering Design and Practice II}

This course, hereafter APSC200, is a one-term course taken by all students in their second year. Learning outcomes for this course are discussed in detail in [2]. APSC200 is project-based, and is delivered in three segments (P0, P1 and P2) over a 12-week term. P0 is a quick, icebreaker design project and team building activity that takes place in week 1 . There is little design instruction; rather P0 provides students with the opportunity for reflection on teaming and the design process before these topics are formally covered in $\mathrm{P} 1$. In the $\mathrm{P} 1$ project, weeks 2-6 of the term, formal instruction takes place, covering the design process and design tools, written and verbal communication, formal and informal presentations, design economics, codes and standards, safety, ethics, and societal/environmental considerations. Student teams chose between three design project topics selected to illustrate the design process. Offered in parallel with the project are lectures and workshops which cover problem definition and scoping, information research, idea generation and creativity techniques, project management, safety, decision making tools (pros/cons table, weighted evaluation matrix) triple bottom line, cost estimation, design assessment and iteration. Project deliverables in P1 include a proposal, interim and final reports, and an oral presentation. Communications workshops are held on a just-in-time basis to support the project deliverables.

APSC200 P2, which is delivered (largely independently) by each department, takes place in the final 6 weeks of the term, and centers on a discipline-specific design project. The objective of $\mathrm{P} 2$ is for student teams to practice with the engineering design tools and methods introduced in P1, while working through a design project chosen to emphasize the skills of their program. This paper focusses on the development and implementation of the P2 project for students in the Queen's Engineering Physics program.

\section{THE P2 PROJECT FOR ENGINEERING PHYSICS STUDENTS}

\subsection{Project Description and Constraints}

Students in Queen's engineering have a free choice of engineering program going into second year. The Engineering Physics (ENPH) program attracts about 65 students each year. Typically, ENPH attracts academically and technically strong students.

The P2 project is designed primarily to reinforce the concepts learned in P1, but also needs to be sufficiently rigorous to meet the technical expectations of students, challenge them, and also provide them with an appreciation of some of the more practical issues that may constrain and limit an engineering design project. Students gain motivation and "ownership" of their project by picking the project themselves within a theme. By having an openended project within a theme, the apparatus is inexpensive and largely provided in advance, and the necessary background is manageable even for students with little experience. The current Engineering Physics P2 project, originally introduced in fall 2014, is described below. Students work with the instructors serving as the fictitious client:

\section{"The Compact Environmental Monitoring Station - an Arduino-based Sensor device".}

Client: Ontario Ministry of the Environment (OMOE) Premise: The concern is the effect that humans are having on the environment - climate change through greenhouse gas emissions is one aspect, of course, but there are others - light pollution, habitat reduction, etc. These may diminish our quality of life and that of future generations.

Advances in technology have provided a new and unique opportunity for gathering environmental data crowdsourcing. The OMOE wants to put cheap and compact environmental sensors in every backyard in Ontario - to measure what could be a multitude of environmental parameters. The data gathered will be used by the OMOE to inform decisions about environmental regulations, policy planning, and public sector investment.

These devices will be cheap and easy to use - and given to Ontario householders who will deploy them in their own backyards or neighborhoods. The information will be collected by the OMOE.

Each student team works for a company that designs "environmental solutions". Each team wants to bid on this project, and the final report and final presentation represent the bid to the client.

Design Constraints: The cost of the device prototype should be under $\$ 100$, run on an Arduino platform using a MatLab interface, and produce "real time" graphical data from the sensor. Additionally, a working prototype must be built, in a time frame of less 
than 4 weeks. This prototype will be used for demonstration purposes during the "bid" to the client.

The design and build of the prototype is key to the project. As mentioned above, the prototype is used to demonstrate a working version of the device to the 'client'. But additionally, the building of a working device is extremely valuable for the following reasons:

- It provides students with a valuable hands-on technical experience, developing practical skills that are necessary for a graduate Engineering Physicist.

- It helps students to understand the true constraints and limitations of a technical design, since designs are often very different "in theory" than in implementation. Nearly every team initially included design ideas that could not be implemented because of practical limitations, which they discovered by trying to build their prototype.

- For the prototype build, students are provided an Arduino, a breadboard and a general selection of electronic components (resistors, capacitors, etc) - as well as some basic sensors (pressure, temperature, $\mathrm{CO}$ ). All other device components need to be ordered. This helped students develop a strong appreciation for "sourcing" engineering components and how to read and understand technical specifications for available products.

- Giving students the freedom to choose a project within a fixed theme provides an opportunity for students' interests and creativity to play a role, while constraining the budget, scale and technical requirements of the course.

- $\quad$ Building a working device provides a challenge that engages and excites the students - prompting them to put in a maximum effort and take pride in their final product.

\subsection{Logistics}

Students work in 14 teams of 4-5 students each the same teams as for P0 and P1, assigned by the course instructor to avoid isolating female students. Two $\mathrm{x} 2$ hour sessions are scheduled for the $\mathrm{P} 2$ project each week, with the first hour mandatory. A lab room is dedicated to this course, and is open to students during normal office hours as well as 4 nights per week until 10:30. Each team has their own dedicated worktable space. All general materials, tools and supplies are centrally located close to a soldering workstation. The course is assigned four TAs. Three of these TAs (senior undergrads/graduate students) are present from the beginning of the EDPS II course and guide and assess the students throughout their P0 and P1 projects. These TAs are responsible for 5 teams each, and do most of the marking for their teams. In addition to these 3 TAs, an additional "technical TA" is hired exclusively for the P2 project; this TA had specific expertise with
MatLab and the use of Arduinos. Finally, students were able to interact closely with a highly skilled technician who assists them with sourcing and ordering device components, as well as providing technical advice and helping with specialized tasks (soldering, etc).

\subsection{Assessment}

$45 \%$ of the APSC200 assessment is allocated to the P2 portion. Table 1 shows the schedule and marks breakdown for deliverables. Note that the course has two separate elements - APSC200 (engineering design) and APSC293 (engineering communication) and that most the deliverables (proposals, reports, etc) are evaluated for both of these.

Of note was the assessment of the prototype. As seen in Table 1 , this was only worth $5 \%$, but was the aspect of the course that generated the most enthusiasm and excitement. In part, this because the mark for the prototype is based on a modified "Kano Model"- type of assessment [3],[6]. Figure 1 illustrates this assessment scheme. The basic Kano diagram of Functionality vs Client satisfaction is shown in the graph (used with permission from [6]) with the "prototype mark" from 1-5 shown on the left-handside.

TABLE 1: STUDENT ASSESSMENT FOR P2

\begin{tabular}{|c|c|c|c|c|}
\hline P2 Deliverable & Due date & $\begin{array}{l}\% \text { mark for } \\
\text { EDPS design }\end{array}$ & $\begin{array}{c}\% \text { mark for } \\
\text { EDPS } \\
\text { communication }\end{array}$ & $\begin{array}{c}\text { Group marks or } \\
\text { individual }\end{array}$ \\
\hline Proposal & Week 8 & $5 \%$ & $5 \%$ & group \\
\hline $\begin{array}{l}\text { Workshop } \\
\text { notebooks } \\
\text { (two)-hand in } \\
\text { by } 10 \mathrm{pm}\end{array}$ & Week 8 & $\begin{array}{c}2 \% \\
\text { (1\% each) }\end{array}$ & - & individual \\
\hline Progress Rep 1 & Week 9 & $2.5 \%$ & $2.5 \%$ & group \\
\hline Progress Rep 2 & Week 11 & $2.5 \%$ & $2.5 \%$ & group \\
\hline $\begin{array}{l}\text { Prototype } \\
\text { (build) }\end{array}$ & Week 12 & $5 \%$ & & group \\
\hline Final Report & Week 12 & $18 \%$ & $25 \%$ & group \\
\hline $\begin{array}{c}\text { Final } \\
\text { presentation }\end{array}$ & Week 13 & - & $10 \%$ & group \\
\hline Attendance & & $10 \%$ & & individual \\
\hline
\end{tabular}

As seen in Figure 1 - the basic "must have" features of the prototype device (one basic working sensor interfaced with an Arduino) would provide a maximum of about 2 marks out of 5 (shown in pink). Additional technical features (multiple sensors, Bluetooth or SD card functionality, batteries or solar cells, calibration) could increase the mark to 4 out of 5 (shown in green/yellow). But to get the perfect score of $5 / 5$, Teams had to include a "wow factor" (shown in blue) something that made their device really stand out - and this generated a huge amount of creative effort from the students. "Wow factor" additions included designed and 3-printing attractive packaging, app interfaces for IPhones or android devices, batteries, solar cells, Bluetooth connectivity, or creating hardwired devices rather than leaving the device on a breadboard. 


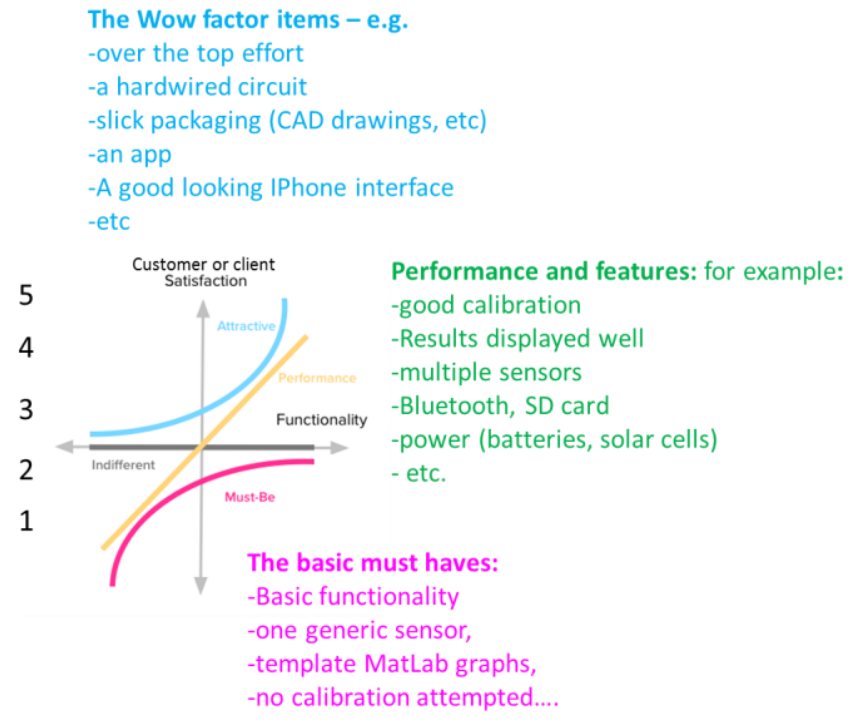

Fig. 1. Assessment of prototype, based on the Kano Model (graph reproduced with permission of [6]). Marks out of 5 are shown on the left. "must do" features (pink) will generate 2/5 marks maximum. Performance and features (yellow) up to $4 / 5$. But to achieve $5 / 5$ marks the prototype must also have attractive "wow factor" feature(s).

\section{P2 PROJECT PROGRESSION}

The 4 stages of the course are:

1) Week 7: Problem definition, brainstorming, research

2) Week 8: Just-in-Time workshops covering basic technical aspects of the design

3) Weeks 9-12: Design and prototype build

4) Weeks 12-13: Report completion, prototype presentation, final client presentation

Each stage, including development, is discussed below.

\subsection{Week 7: Problem definition, brainstorming and research}

The first Week 7 session begins with a short overview lecture to cover the problem/task (as mentioned above in section 2.0) deliverables, and timelines. Teams are given the remainder of the timeslot for idea generation, considering the following - "Identify an environmentalrelated question/problem/issue that would benefit from a widespread data gathering from across Ontario". Enthusiasm runs high, as teams begin covering any available surface with post-it notes. After some initial brainstorming, teams conduct cursory research to narrow down the number of ideas. By the end of the first session, each team member leaves with one or two "potential" environmental parameters to research - answering the question - "Can this parameter be measured using compact and cheap sensors that can interface with an Arduino microcontroller?"

Students bring their findings back to their team in the second session of Week 7. As they discuss their research and narrow down their design options they are encouraged to use the diagram in Figure 2 (which was introduced in P1 [5]) to ensure that they consider all of the functional requirements in their problem definition. Teams also use this time to begin work on their Proposal, which is due at the end of Week 8 .

\subsection{Week 8: Just-in-Time workshops covering basic technical aspects of the design}

In order to produce a successful design and working prototype for this project, students require a working knowledge of Arduinos, breadboards, and current-limiting resistor circuits, in addition to being able to follow and comprehend Arduino and MatLab code. Only about $20 \%$ of ENPH students bring this background into the course, therefore week 8 contains

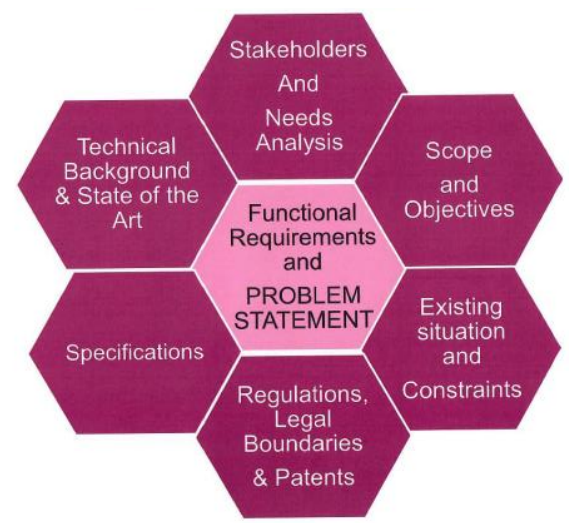

Fig. 2. Summary of functional requirements and problem definition (reproduced with permission by David Strong [5].

two just-in-time "workshops" to upgrade student skills to a common, basiclevel. The two workshops are:

Workshop 8a: Arduino Circuit Basics: Students build an Arduino-based blinking LED and use a CdS photocell to detect the light - reading the output voltage on Arduino serial monitor, with example code modified from [7].

Workshop 8b: Arduino + MatLab Serial

Communication: Students build a Arduino-based temperature sensor device and use MatLab to interface it with a laptop and display data in real time, with example code modified from [8].

From 2014-2017, the workshop tasks were completed "in teams" - which meant that the exercise was often dominated by the one or two students in each team with the most technical expertise. Additionally, students were not required to prepare for the workshops in advance, and this 
lack of preparation necessitated significant instructor intervention in order to achieve a working device.

To address these problems and create a more effective learning experience for all of the students in the course, in 2018 the format was changed so that students complete the workshop exercises as a pair, with one Arduino + breadboard between them. Additionally, a "flipped workshop" model was adopted for the Week 8 workshops, with most of the content presented and reviewed on-line by students the previous evening. The prelab material for the new flipped workshops is covered below, using Week 8a material as an example.

3.2.1 Overview video: short $(<2$ minute) videos provide a step-by-step overview (in voice-over PowerPoint) of what the students will complete in each workshop. Figure 3 shows a typical video screenshot.

3.2.2 On-line prelab content and quizzes: these covered all of the background content needed for each workshop. For example in Workshop 8a the topics were:

- Resistor colour coding

- LED circuits

- Using a breadboard

- The Arduino microcontroller - hardware

- The Arduino microcontroller - software A screenshot example is shown in Figure 4.

3.2.3 Downloading and reviewing all software: Students download all Arduino sketches and MatLab code in advance, and review it as part of the prelab. A screenshot example is shown in Figure 5.

3.2.4 e-Lab notebook template: during the workshop, students work through an e-lab notebook template that they download the night before. This contains instructions for building the devices and "blank boxes" to include their own working notes, results, and answers to questions. A screenshot of part of the Week 8a template is shown in Figure 6.

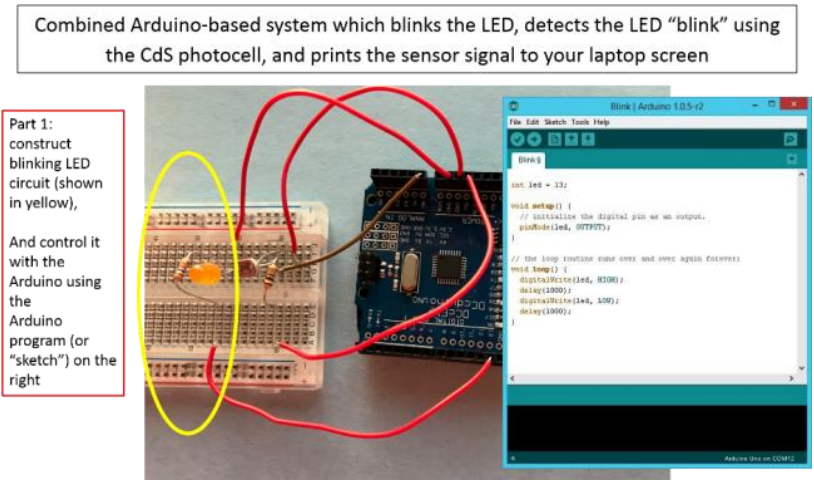

Fig. 3. Screenshot from the overview video from the Week 8a workshop. Video format is voice-over PowerPoint.

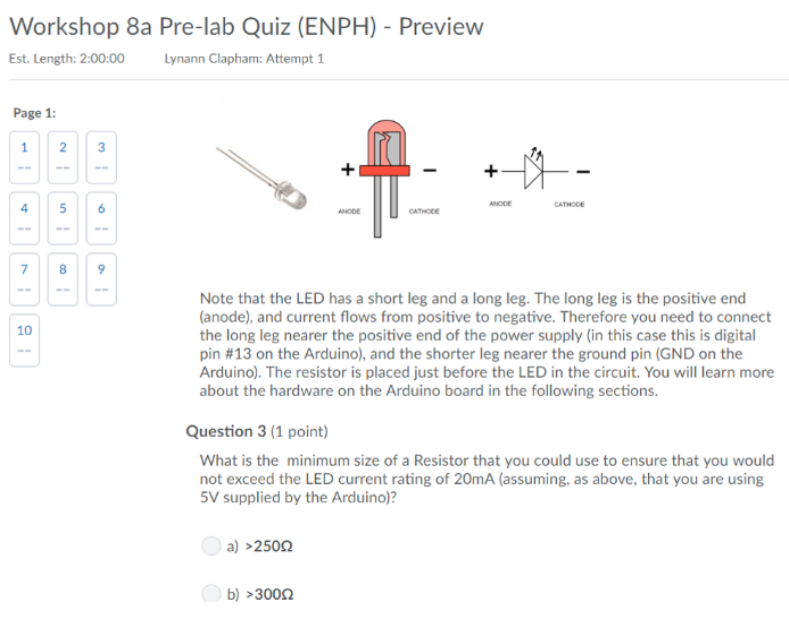

Fig. 4. Screenshot from the on-line prelab content for LED circuits, including content (above) and a quiz question.

The efficacy of the "flipped workshop" model introduced in fall 2018 was not formally assessed. However, it was noted that the students were FAR less dependent on the instructor and TAs to walk them through the workshop exercises. All students were able to build a satisfactory sensor device and get it working. The main problem (which affected about $10 \%$ of the students) was that sometimes the Arduino and Matlab software did not install correctly. In future years, a few desktop computers will be available with this software installed so that students will not waste time with installation problems.

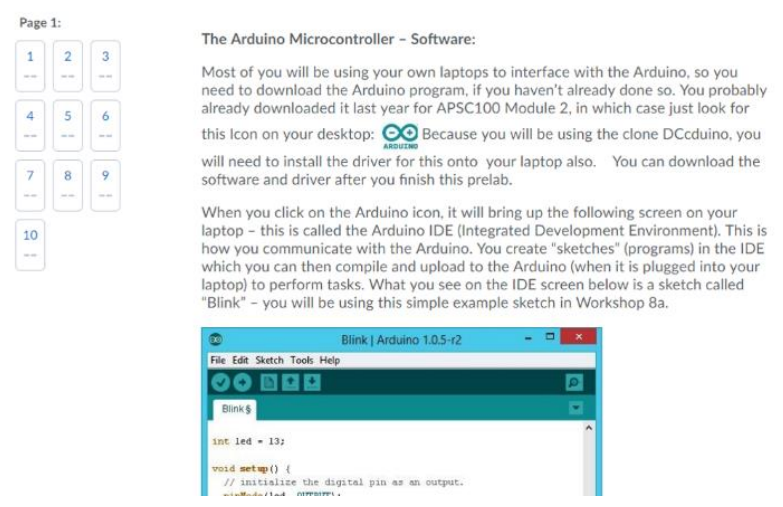

Fig. 5. Screenshot from the on-line prelab content which covers downloading and reviewing the Arduino software (sketches) 


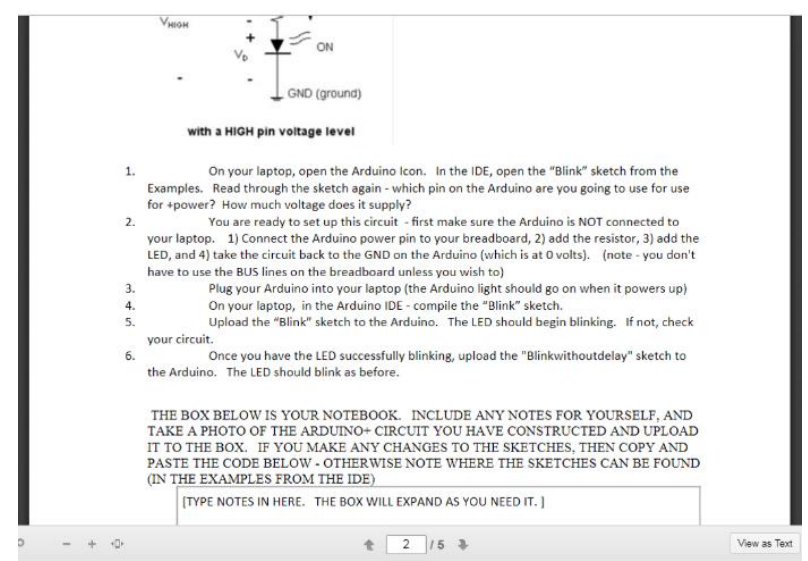

Fig. 6. Screenshot from the e-lab notebook template students downloaded and then used to work through the workshop. Instructions are followed by fill-in-the-blank boxes for notes, results, photos, etc.

\subsection{Weeks 9-12: Project Design and Prototype Build}

In the final 3.5 weeks of the project, work on the design proposal and prototype building continue in parallel. On the design proposal side, teams work within the scope of their project to flesh out their design, again using idea generation methods for smaller aspects such as power and communication options. Students also worked on elements of economics, safety, codes and standards, ethics, and societal environmental considerations. As seen in Figure 1, progress reports were due at the end of weeks 9 and 11.

The Week 8 workshops (section 3.2) provided an excellent springboard for the prototype-build for all teams: the small number of "technically weak" teams could readily build a prototype - simply by replacing the "workshop 8b device" sensor with a sensor of their own choice. However, for groups with one or two technically strong members, the Week 8 workshops brought all other team members to the point where they could contribute to the prototype and expand the technical complexity of the design - adding battery systems, communication options, apps, 3-D printing, etc. Of particular note was how the "prototype build" helped to inform the design process. Students developed an appreciation for the frustrations of sourcing, and often obscure technical specifications. "Building" also helped all students appreciate the many practical limitations that limit a true, "engineering" design. For example, one group began with a plan to design a "light sensor" to determine optimum placement of a backyard solar power generator. They ordered a "luminosity sensor" for their prototype that they believed met all of their necessary specifications. They were shocked when it arrived a few days later; they opened the packaging to find that the device was smaller than a grain of salt - such that soldering it would have been impossible! They were not able to source a larger sensor with similar specifications, so they had to modify their design accordingly.

\subsection{Weeks 12-13: Report completion, prototype presentation, final client presentation}

The "prototype build" was completed in 3.5 weeks culminating with a "prototype presentation" held in the second 2 hour session in week 12 . As mentioned in section 2.2 , students knew from the outset that they would be evaluated using a modified "Kano model" and as such worked enthusiastically to build technical complexity and a "Wow factor" into their final prototype. The final report was due at the end of week 12, with the "client presentation" held 4 days later, in week 13.

\section{EXAMPLES OF ENPH APSC200 P2 PROJECTS}

Below are summaries of three of the $\mathrm{P} 2$ projects designed and built during the final 4 weeks of the Fall 2019 course:

Detecting Heat Loss in Ontario Residences: This team designed and built a prototype device that combined the Arduino Uno microcontroller with a 64-pixel thermal camera sensor. They created MatLab code to produce a 2D "heat loss map". The device was powered by a rechargeable battery, and communicated to an Android cellphone using an Android app (written by the team) through an Arduino Bluetooth shield. The team also designed 3D printed packaging for this device. The prototype device was built for less than $\$ 60 \mathrm{Cad}$ (excluding the cost of the Arduino Uno).

Soil Data Collection for Community Garden Implementation in Ontario: This team focussed their efforts on a device to help select ideal locations for community gardens. Detectors were implemented to monitor three environmental parameters critical for plant growth - luminosity, soil moisture, and soil temperature, and packaging was 3D printed for their device. The team wrote pre-processing Arduino software to condense the data for transfer only once daily, which extended the rechargeable battery life. They used an Arduino Bluetooth shield for communication, and designed an appealing, user-friendly IPhone app interface. The cost of the prototype device (excluding the Arduino Uno) was \$64 Cad.

The WASP (Wind And Solar Power) detector: This team designed and built a detector for determining ideal locations for small scale, "backyard" wind and solar power generating stations. Significant effort went into designing 
the power electronics for two Li-ion batteries, including a DC converter and charge protection boards for monitoring the batteries and keeping them within safe operating limits. A solar cell was used both as a solar detector (via measurement of the open circuit voltage) as well as for charging the Li-ion batteries. The device also incorporated an anemometer to measure wind speed. An Arduino SD card (shield) was used for data storage, with a Python script written for preprocessing and storing the data. The cost of the prototype device (excluding the Arduino Uno) was $\$ 90$ Cad.

\section{STUDENT FEEDBACK}

The ENPH P2 portion of APSC200 has been offered in its current form for 5 years, with the exception of the week 8 "flipped workshop" format which was introduced in Fall 2019. Three different instructors have taught this course over this 5-year period. Evaluation scores for the past 3 years are shown below, obtained from the Queen's University USAT (University Survey of Student Assessment of Teaching):

Question: Overall, this is an excellent course:

Scores over 3 years: $3.9-4.0 / 5.0$

Question: Overall, this instructor is an effective teacher:

Scores over 3 years: 4.3-4.5/5.0

Question: The instructor presented the material clearly:

Scores over 3 years: 4.1-4.3/5.0

Question: The workload in this course was reasonable and appropriate:

Scores over 3 years: $3.9-4.1 / 5.0$

The USAT scores above are all higher than that of the mean for other APSC courses, which range from 3.5-3.6/5.0.

The learning experience from the APSC200 course is summarized by second year ENPH student Justin Bonal, who headed up the team that won the Junior (years 1-2) Design Competition at the Ontario Engineering Design Competition in January 2019 [1].

"Even though the APSC 100 and 200 courses we take as engineering students at Queen's are extremely rigorous, they are fully the reason why we won this competition. They really drilled the design process into our heads so when the competition came around, the process was natural to us. We managed to get a $100 \%$ scale across the board, being graded on the performance of the prototype, our team working abilities, our presentation, and the originality of the design".

\section{References}

[1] Justin Bonal, quotation "2019 OEC Junior Design Winners" posted Jan 21, 2019 website Department of Physics, Engineering Physics and Astronomy https://www.queensu.ca/physics/2019-oecjunior-design-winners

[2] Brian Frank, David Strong, Rick Sellens, and Lynann Clapham, "Progress with the Professional Spine, A Four-year Engineering Design and Practice Sepquence" in Proc. $20128^{\text {th }}$ International CDIO Conf. (Brisbane, Australia, July 1-4, 2012).

[3] Noriaki Kano, Seraku Nobuhiku; Takahashi Fumio, Tsuji Shinichi (April 1984). "Attractive quality and must-be quality". Journal of the Japanese Society for Quality Control (in Japanese), vol 14, no. 2, pp 39-48, 1984.

[4] David S. Strong and Brian Frank, "A Novel Facultywide Approach to Teaching Second Year Engineering Design and Professional Practice" in Proc. CEEA Canadian Engineering Education Conf., CEEC12, (Winnipeg, MB, June 17-20, 2012), Paper 56, 2012.

[5] David Strong, APSC200 Lecture notes, private communication.

[6] Daniel Zacarias, "The Complete Guide to the Kano Model, The Complete guide to Prioritizing Customer Satisfaction and Delight". ,https://foldingburritos.com/kano-model/

[7] https://arduino.cc, retrieved September 2014.

[8] http://www.matlabarduino.org/serialcommunication.html, retrieved September 2014. 